УДК 379.81

DOI: $10.32343 / 2409-5052-2021-15-3-335-344$

Оригинальная статья

\title{
Формирование имиджа организации социально-культурной сферы как эффективный инструмент конкурентоспособности
}

\author{
Н. В. Молчанова \\ Волгоградский государственньй институт \\ искусств и культуры, г. Волгоград \\ natmol.v@mail.ru,https://orcid.org/0000-0002-1794-9621
}

\begin{abstract}
Аннотация
В данной статье рассматриваются процессуальные основы формирования имиджа организаиий сочиально-культурной сферы как эффективного инструмента конкурентоспособности на рынке культурных услуг. Предмет исследования: формирование имиджа и поиск путей и средств для большей привлекательности облика культурных организаций как повышение эффективности их деятельности. Цель: определить современные инструменты повышения престижа учреждения, такие как маркетинг, реклама и пиар в сфере культуры, которые необходимо использовать для привлечения интереса потребителей, что станет гарантией развития и расширения спектра сочиально-культурных услуг предприятия. Учреждения социально-культурной сферы должны находить возможность для самостоятельного формирования и поддержания положительного облика. Все эти действия необходимы для конкурентоспособности, продуктивности, а также узнаваемости, привлекательности со стороны общественности, спонсоров и бизнес-партнёров, вследствие чего - востребованности услуг. Деловая репутация любого учреждения сочиально-культурной сферы, его становление и успешная деятельность сегодня во многом зависят от взаимодействия с общественным мнением.
\end{abstract}

Ключевые слова: формирование, имидж, организаџия, социально-культурная сфера, инструмент, конкурентоспособность, культура, услуга

Для цитирования: Молчанова $H . \quad B$. Формирование имиджа организации социально-культурной сферы как эффективный инструмент конкурентоспособности // Педагогический ИМИДЖ. 2021. Т. 15. № 3 (52). С. 335-344 DOI: $10.32343 / 2409-5052-2021-15-3-335-344$

\section{Creation of an Image of a Sociocultural Institution as an Effective Tool of Competitiveness}

N. V. Molchanova

Volgograd State Institute of Arts and Culture, Volgograd

Original article

Abstract.

This paper examines the procedural basis for building an image of sociocultural organiza- 
tions as an effective tool for competitiveness in the market for cultural services. The study focuses on image projection and the search for ways and means to increase the attractiveness of the image of cultural organizations to improve their performance. The research aims to identify modern tools to enhance institution prestige, including marketing, advertising, and public relations in the culture field, which are necessary to attract consumers. These tools will guarantee the development and expansion of a range of sociocultural services of the enterprise. These institutions should find an opportunity to independently build and maintain a positive image. All these measures are necessary to make these institutions competitive, efficient, recognizable, and attractive to the public, sponsors, and business partners, which will create demand for their services. Today, the establishment of the business reputation of any sociocultural institution and business success largely depend on interaction with public opinion.

Keywords: creation, image, sociocultural institution, tool, competitiveness, culture, service

For citation:Molchanova N. V. Creation of an Image of a Sociocultural Institution as an Effective Tool of Competitiveness. Pedagogicheskiy IMIDZH = Pedagogical IMAGE. 2021; 15(3):336-344. DOI: 10.32343/2409-5052-2021-15-3-335-344 (In Russ.).

\section{Введение}

Актуальность заявленной в статье проблемы обусловлена переменами, которые сегодня претерпевают социально-культурные учреждения в своей деятельности. Данные изменения связаны с их общественным значением, а именно они не только продолжают работать как центры досуга, они являются активными участниками социально-культурных и экономических процессов.

Условия работы социально-культурных организаций представляют собой равенство всех форм собственности, отсюда не только государственные, образовательные, организации здравоохранения и др. представляют собой сеть государственных (федеральные, региональные и местные) и негосударственных структур, это касается и предприятий социально-культурной сферы [1, с. 48].

Для учреждения культурно-досугового типа большое значение отводится имиджу и репутации. Аудитория, анализируя рынок предложенных услуг, первым делом оценивает организацию исходя из её сведений и информации о ней.

\section{Обзор литературы}

Основу теоретического исследования экономики культуры, имиджа предприятий и организаций социально-культурной сферы, социально-культурного менеджмента в рамках данной статьи составили труды С. Г. Коленько, Г. Л. Тульчинского, С. В. Герасимова, Т. Е. Лохиной, Л. Н. Галенской, Е. Л. Шековой, Н. А. Михеевой, Т. В. Артемьевой, В. Д. Пономарева, В. В. Туева, Д. В. Шамсутдиновой, Н. Ф. Максютина, В. Е. Новаторова, Е. И. Григорьевой и др.

Имидж каждой организации в сфере культуры имеет свой индивидуальный, самобытный характер со своей уникальностью, преимуществами в деятельности и рассматривается как интегральное качество. Позитивный облик помогает сформировать доверие к учреждению, что в будущем будет содействовать росту престижа и привлечению большей аудитории, а это приводит к повышению авторитета, влияния и экономическому благополучию [2, с. 10].

Выделяют три составляющие позитивного имиджа организации культуры: поведенческая, коммуникативная, визуальная.

В настоящее время важным является формирование имиджа организации социально-культурной сферы. Дело в том, что непредвиденный, незапланированный результат деятельности учреждения культуры мгновенно вызывает недопонимание и 
продолжительные ошибочные суждения со стороны потребителей услуг.

Имидж организации культуры содержит в себе практические функции ценностного, направленного, технологического вида. Ведущие функции имиджа организации социально-культурной деятельности:

- особое значение уделяется личным и общим ценностям (аксиологическая);

- возможность сообщать о наборе тех качеств учреждения, которые делают его особым, уникальным, самобытным (информационная функция);

- выражается предоставленной «выгодной» информацией о качестве работы учреждения, его общедоступности, продуктивности (коммуникативная);

- основывается на распределении акцентов: «Почему именно эта организация, a не аналогичная?», «С помощью чего учреждение выделяется на фоне других (дифференцирующая функция)?»;

- организуется за счёт соединения членов управления деятельностью, покупателей услуг не выходя за пределы одной социально-культурной, информационной области (объединительная);

- создание необходимого образа организации для потребителей, отличного от остальных учреждений данного типа (функция позиционирования);

- создание необходимости участвовать в жизни, работе организации с целью приобщения к культуре и получению культурных продуктов и услуг (мотивационная функция) [3, с. 68].

Все вышеперечисленные функции выполняют своё предназначение в формировании образа привлекательного, востребованного учреждения социально-культурной сферы.

Разработкаимиджакаквозможностьповысить востребованность, привлекательность учреждения в глазах аудитории не является гиперсложным и затратным способом привлечения внимания.

Для разработки имиджа учреждения культуры можно выделить следующие исключительные качества, которых необходимо придерживаться:

1. Системность. Системный потенциал заключается в том, что имидж организации можно создать методами и приёмами самой социально-культурной деятельности. Посредством системности учреждение приобретает те индивидуальные, неповторимые качества, которые способствуют целостности, креативности, саморазвитию и дают мощный толчок к приобретению нового, наиболее значимого, престижного статуса организации.

2. Ресурсная база. Положительный облик организации складывается из следующих характерных форм ресурсов: творческая, организационная, методическая, моральнонравственная. Особое место в ряду специфических ресурсов занимают история, традиции учреждения; опыт, подготовка и квалификация специалистов, креативных групп.

3. Принцип честности и открытости. На данный момент открытость - это тот параметр, без которого невозможна деятельность ни одного учреждения культуры, ведь именно этот принцип результативен в сотрудничестве с обществом. Доступный, честный, открытый досуг будет конкурентоспособным, его можно будет осуществить совместно с организациями общественного, политического, государственного типа, со средствами массовой информации (СМИ), творческими коллективами и др.

4. Специфика производимого продукта. Особенность культурного продукта (его специфика) - отличительная черта формирования имиджа организации культурнодосугового типа. Культурный продукт может иметь различную материальную базу, культурную ценность, эстетическую роль, однако основной его параметр - источник духовного и интеллектуального наслаждения - будет неизменен.

5. Особенности места. Местоположение учреждения культуры играет большую роль в специфике построения работы. Например, организации, находящиеся в городах 
- культурных центрах, могут наиболее продуктивно развивать имидж, пользуясь своим выгодным территориальным положением. Что касается социально-культурных учреждений, местоположение которых удалено от центров культуры, их построение и развитие имиджа могут носить иной характер (развитие регионального компонента, культуры местности, культурное, историческое, природное своеобразие и т. д.).

6. Потребности и своеобразие аудитории. Аудиторию по целям можно разделить на две группы: это «посетители учреждения» и «участники деятельности творческой организации». Для первой группы важно уделить время и внимание себе, повысить свою самооценку, повысить престиж, свой статус, укрепить имидж. Следующая же группа целью своей деятельности видит саморазвитие, самореализацию, общение, получение эстетического удовольствия от творческого продукта, созданного непосредственно с их участием [4, с. 67].

Имидж организации социально-культурной сферы - средство деятельности, направленноенарезультативнуюиконкурентнуюработуучреждения.Самопрезентации, узнаваемость часто реализуются на пресс-конференциях, брифингах, в беседах с участниками, настоящими и будущими, на фото- и видеопредставлениях и др.

Позиционирование открывает возможности для разработки положительного облика организации, причём основное внимание потребителя можно направить на качества, характеристики среды, которые способны развить позитивные перспективы работы.

На сегодняшний день система социально-культурных учреждений рассматривается как одна из ведущих сетей по организации свободного времени и досуга населения России. В официальных документах фиксируются позитивные тенденции, свидетельствующие о повышении творческого и инновационного потенциала учреждений.

Однако современные исследования указывают на признаки кризиса между культурными организациями и потребителями услуг.

\section{Материалы и методы}

В целях выявления влияния имиджа организации социально-культурной сферы на выбор потребителя того или иного учреждения социально-культурной сферы было проведено исследование среди посетителей пяти учреждений культуры города Волгограда (Государственное бюджетное учреждение культуры (ГБУК) «Волгоградский планетарий»; ГБУК «Волгоградский государственный Новый экспериментальный театр»; ГБУК «Волгоградский областной центр народного творчества»; ГБУК «Волгоградская филармония»; ГБУК Волгоградский государственный театр «Царицынская опера»). Исследование проводилось в виде письменного опроса при участии 150 респондентов в возрасте от 18 до 65 лет. Анкета была разработана с учётом специфики деятельности организаций, все учреждения, выступившие в роли базы исследования, являются бюджетными, т. е. не осуществляющими деятельность на коммерческой основе.

В опроснике было заявлено несколько групп критериев, а также основных блоков, влияющих на выбор организации социально-культурной сферы потребителями культурных услуг.

Первый блок вопросов был направлен на оценку внутренней среды организации, а также отношения респондентов к значимости качества предоставляемых услуг организациями социально-культурной сферы, а именно к их разнообразию, уровню организации технологического процесса, соответствия интересам потребителей. Результаты исследования представлены на рисунке 1. 


\section{Критерии оценки протребителями} внутренней среды организации

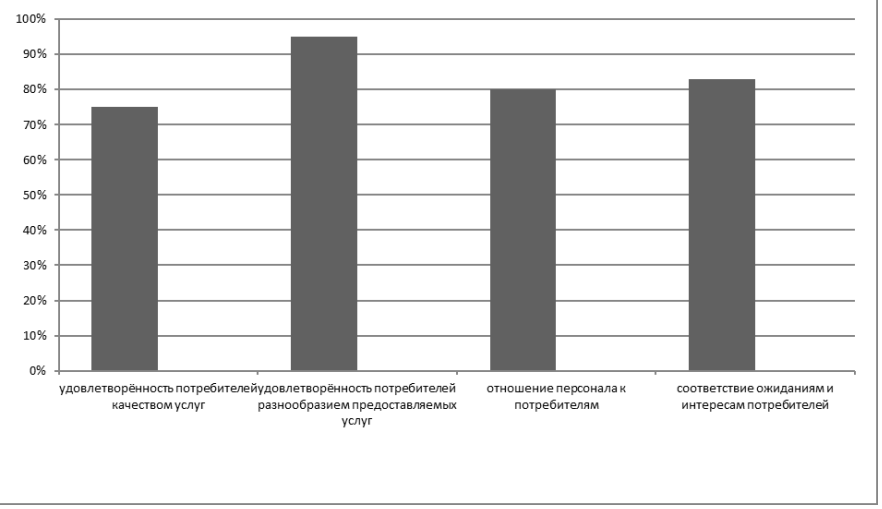

Рис. 1. Результаты опроса потребителей по оченке внутренней среды организации

Fig. 1. Results of a consumer survey to assess the internal environment of the organization

Второй блок вопросов был обусловлен взаимодействием организации социально-культурной сферы с внешней средой, а именно направлен на информационную политику, маркетинговые технологии, выяснение реакции на экономические трансформации и т. д. Результаты исследования представлены на рисунке 2.

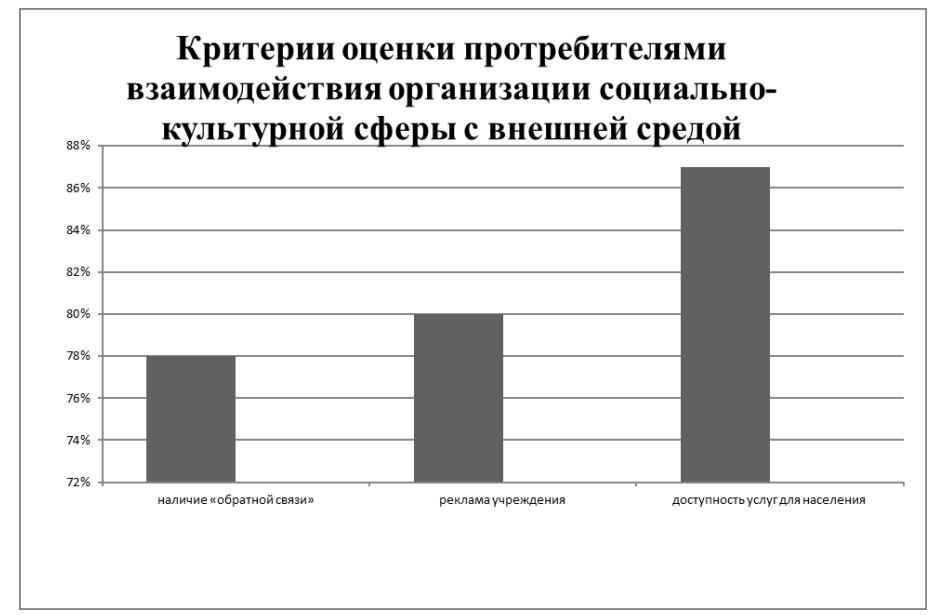

Рис. 2. Результаты опроса потребителей по оценке взаимодействия организации с внешней средой

Fig. 2. Results of a consumer survey to assess the organization's interaction with the external environment

В результате исследования были выявлены наиболее значимые критерии:

1) удовлетворённость потребителей качеством услуг;

2) удовлетворённость потребителей разнообразием предоставляемых услуг;

3) отношение персонала к потребителям;

4) наличие «обратной связи»;

5) реклама учреждения;

6) доступность услуг для населения;

7) соответствие ожиданиям и интересам потребителей. В обобщённом виде результаты исследования представлены на рисунке 3. 


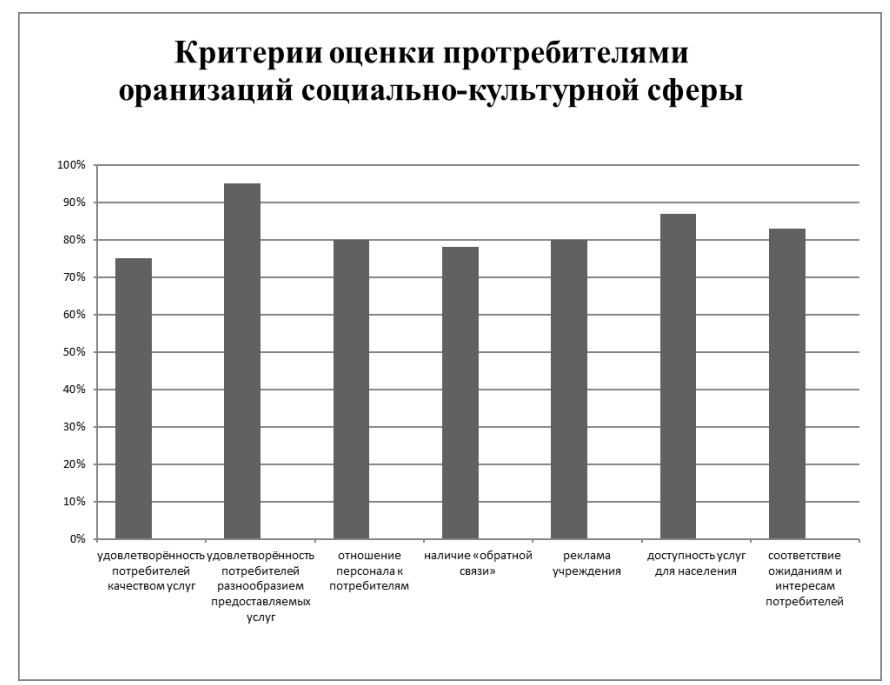

Рис. 3. Результаты опросника посетителей учреждений культуры г. Волгограда

Fig. 3. Results of the questionnaire of visitors of cultural institutions of Volgograd

Имидж организации напрямую зависит от ценностей и приоритетов общества, которые пропагандируются в определённый период времени. Имидж учреждения социально-культурной сферы должен быть гибким, иметь способность подстраиваться под изменчивое, развивающееся общество, его интересы, потребности. Так, на сегодняшний день особую ценность представляет свободное от работы, учёбы, бытовых дел время - время для досуга. Перед потребителями услуг возникает вопрос о выборе учреждения социально-культурной деятельности, которое сможет удовлетворить их культурные потребности. Отсюда организация должна позаботиться о своём положительном облике с целью привлечения потребителей культурных услуг.

\section{Результаты исследования}

Подводя итоги проведённого исследования, мы пришли к выводу, что выход из сложившейся ситуации в повышении эффективности деятельности и привлекательности учреждений культуры, использовании креативных технологий, повышении уровня профессионализма специалистов, привлечении дополнительного внебюджетного финансирования.

Имидж и конкурентоспособность организации неразрывно связаны. Положительный облик способствует повышению престижа, авторитета и влияния, без чего невозможно получение высокого рейтинга [5, с. 130].

Выделяют следующие составляющие имиджа:

1) кадровая политика (грамотное руководство, высокий профессиональный уровень персонала, работа над улучшением условий профессиональной деятельности, баланс профессиональных и межличностных отношений между сотрудниками);

2) внешний и внутренний дизайн-проект;

3) реклама;

4) выходящая за пределы учреждения внешняя документация, которая отвечает основным требованиям стандартов;

5) культурные нормы внутри учреждения (стиль общения, результативность работы, характерные особенности и традиции организации);

6) ответственность за общественные последствия; 
7) благотворительная работа (организация и проведение мероприятий благотворительного характера; спонсорская помощь культурным работникам; публикация не рекламных брошюр; культурные программы, цель которых заключается в получении полезной и интересной информации социумом и каждым отдельным человеком) [6, с. 34].

Этапы разработки эффективного имиджа организации социально-культурной сферы:

1) проведение анализа действующего облика учреждения через ознакомление с отзывами и суждениями потребителей культурных услуг;

2) ориентир на интересы и особенности потребителей услуг с обязательным рассмотрением и адаптацией разработанного имиджа;

3) необходимость уделять особое внимание отрицательным действиям конкурентов и иных лиц в отношении данного учреждения культуры;

4) организация координирующих и регулирующих программ, направленная на поддержание и рост положительного облика организации;

5) ознакомление с информацией об имидже из уст потребителей услуг;

6) регулирование пиар-акций, основанных на истинном или разработанном имидже, с целью увеличения конкурентоспособности организации [7, с. 273].

Эффективный имидж учреждения культуры всегда должен опираться на следующие принципы:

1) только подлинные достижения организации культуры идут в основу построения положительного облика, который будет притягивать, а не отталкивать аудиторию;

2) положительный облик создаётся для определённого круга потребителей;

3) особое внимание необходимо уделять индивидуальности и самобытности имиджаучреждения,именноотличительныечертыисоставляютконкурентоспособность организации;

4) имидж должен быть прост, но запоминаем, оригинален, но понятен аудитории. Постоянство имиджа - важнейший принцип, изменения должны быть незначительными;

5) социальные, психологические, экономические факторы не должны разрушать благополучный имидж, отсюда выходит понятие о гибкости облика организации.

На сегодняшний день положительный имидж могут иметь организации коммерческого и некоммерческого типа. Рассмотрим учреждения социальнокультурной сферы, которые являются в основном некоммерческими.

Предприятия социально-культурной сферы представляют собой область услуг, выполняют работу по формированию, развитию культуры, творчества; обеспечивают духовную, социально-культурную стабильность общества [8, с. 45].

Деятельность по разработке положительного облика учреждения направлена на формирование успешной связи организации с обществом, при которой происходит трансляция востребованной, правдивой и устойчивой информации о культурном предприятии. Все культурные программы организации должны идти с нужным посылом, который сформирует необходимое впечатление, вызовет положительную реакцию и нужное впечатление. Отсюда следует, что особое внимание необходимо уделять ораторам, которые выходят на контакт с аудиторией. Форма подачи информации и обстоятельства имеют также колоссальное значение, ведь неточное действие или необдуманное слово - дело секунды, а для исправления ошибки требуются большое количество времени и значительные усилия.

Для формирования и поддержания имиджа нередко приходится обращаться к специальным пиар-мероприятиям, которые способны выполнять информационные и эмоциональные задачи:

1. Взаимодействие со СМИ. Журналист, работающий с учреждением 
культуры, должен быть осведомлён в этой области, деятельность его должна иметь лояльный характер. Важно заинтересовать специалиста, ведь если он сам испытывает неподдельный интерес к культурным услугам организации, то через свою профессиональную деятельность он сможет привлечь внимание потребителей.

2. Информация об учреждении в интернет-пространстве:

- создание корпоративного сайта организации;

- проведение рекламных кампаний (почтовые рассылки);

- работа на единой платформе специализированных сайтов-порталов;

- создание и последующее размещение информации на порталах социальных сетей. Сайты социальных сетей заменяют привычное нам живое общение, объединяют людей в группы по потребностям и интересам, где они активно общаются, делятся опытом, мнениями. Мессенджеры такого уровня способны не только организовывать общение в рамках учреждение - аудитория, но и формировать условия общения потребителей услуг между собой, тем самым увеличивать целевую аудиторию. Организация такой открытой социальной площадки не требует финансовых вливаний, что является большим плюсом для учреждения социально-культурной деятельности. Социальные сети имеют ещё одно большое преимущество - привлечение внимания молодёжи и представителей среднего поколения к организации, зачастую активной аудиторией является и люди предпенсионного и пенсионного возраста [9, с. 33].

3. Организация пиар-программ и мероприятий. Событийный маркетинг как метод разработки позитивного облика достаточно давно применяется в построении имиджа учреждения культуры. Применение таких приёмов продвижения предприятия заключается в проведении актуальных и инновационных программ, при которых происходит контакт с аудиторией. По итогам такого рода мероприятий учреждение становится наиболее конкурентоспособным, приобретаются индивидуальные, новаторские черты, и, как следствие, его деятельностью начинает интересоваться потребитель.

Мероприятия событийного маркетинга разрабатываются с определённой целью, для определённой аудитории и для конкретного момента. К такому роду программ можно отнести дни открытых дверей, отчётные концерты, разговоры со зрителями, наиболее действенными и современными являются пресс-конференции и флеш-мобы.

\section{Заключение}

Прежде чем выбрать организацию культурно-досугового типа, потребитель анализирует рынок предложений культурных услуг и делает вывод об учреждении исходя из полученной информации. Поэтому именно формированию имиджа и репутации предприятия отводится большое значение. Работа над положительным обликом включает в себя постоянное внимание коллектива, финансовые затраты и продолжительное время. Устойчивый имидж учреждения социально-культурной сферы является конкурентным преимуществом и гарантом стабильности при появлении конфликтных и нестандартных ситуаций.

Таким образом, чем известнее организация социально-культурной сферы, тем большей внешней поддержкой она пользуется. Такие приоритеты открывают возможности для организации городских и государственных культурных программ и участия в них, для получения спонсорской помощи от предприятий. Положительный облик не только является показателем успешности учреждения, он мотивирует работников на достижение наилучших результатов своей деятельности, поддерживает хорошие взаимоотношения коллег, препятствует постоянной смене кадров организации. О наличии и эффективности имиджа можно также сделать вывод исходя из удовлетворённости своей профессиональной деятельностью работников учреждения. Прямое отношение сотрудника к положительному облику организации вызывает чувство гордости, повышает статус как организации, так и работника. 
Отсюда - положительный имидж учреждений социально-культурной сферы: доказательство исключительности культурных услуг, востребованности целевой аудиторией и рынком в целом.

Автор прочитал и одобрил окончательный вариант рукописи.

\section{Список источников}

1. Куликова Т. И. Корпоративный имидж организации: Учебное пособие. Тула : Имидж Принт, 2017. 110 с.

2. Салынина С. Ю. Системный подход к управлению имиджем организации социально-культурной сферы // Модернизация культуры: от человека традиции к креативному субъекту: Материалы V Междунар. науч.-практ. конф., Самара, 29-30 мая 2017 г.: в 2 ч. Самара : Самар. гос. ин-т культуры, 2017. Ч. 2. С. $270-274$.

3. Азина А. Г. Формирование имиджа организации социально-культурной сферы // Экономика и общество: перспективы развития: сб. материалов II Всерос. науч.-практ. конф.; 9 апреля 2018 г., Сызрань. Киров : Изд-во МЦИТО, 2018. С. 9-11.

4. Федосова И. В. Имидж педагогического вуза в социокультурном пространстве региона // Педагогический ИМИДЖ. 2018. № 2 (39). С. 128-137.

5. Доронина И. Н. Оценка качества сайта библиотеки как канала межкультурной коммуникации // Вестник Казанского государственного университета культуры и искусств. 2019. № 1. С. 30-37.

6. Панасюк А. Ю. Формирование имиджа: стратегия, психотехнологии, психотехники. М. : Омега-Л, 2009. 266 с.

7. Сатубалдин А. К. Прогрессивные тенденции в развитии современного музейного дела // Вестник Казанского государственного университета культуры и искусств. 2019. № 2. С. 42-48.

8. Симонова И. Ф. Особенности формирования имиджа учреждения культурно-досуговой сферы // Научные исследования: от теории к практике. 2015. № 4 (5). С. $273-278$.

9. Депелян Р. А. Проблемы управления: теория и практика. Факторы, влияющие на формирование внутреннего имиджа организации // Государственное управление. 2017. Вып. № 64. С. 68-81.

\section{References}

1. Kulikova T.I. Korporativnyj imidzh organizatsii [Corporate image of the organization] / Manual. Tula. Izd-vo: Imidzh Print [Image Print Publishers], 2017. 110 p. (In Russian).

2. Salynina S. Yu. Sistemnyj podkhod k upravleniyu imidzhem organizatsii sotsial'no-kul'turnoj sfery [A systems approach to managing the image of sociocultural organization]. «Modernizatsiya kul'tury: ot cheloveka traditsii k kreativnomu sub"ektu». Materialy V Mezhdunar. nauch.-prakt. konf., Samara, 2017 g. [Modernization of culture: from a person of tradition to a creative subject: Proceedings of the V International Scientific and Practical Conference, Samara, May 29-30, 2017]: V. R-2. Samara: Samara State Institute of Culture, 2017. C. 2. Pp. 270-274. (In Russian).

3. Azina A. G. Formirovanie imidzha organizatsii sotsial'no-kul'turnoj sfery [Creation of the image of the sociocultural organization]. Ekonomika i obshchestvo: perspektivy razvitiya: sbornik materialov II Vserossijskoj nauchno-prakticheskoj konferentsii [Economy and Society: Prospects of Development: Proceedings of the $2^{\text {nd }}$ All-Russian Scientific and Practical Conference] (April 9, 2018, Syzran) / Kirov: Publishing House of Interregional Center of Innovation Technologies in Education, 2018. Pp. 9-11. (In Russian). 
4. Fedosova I. V. Imidzh pedagogicheskogo vuza v sotsiokul'turnom prostranstve regiona [The image of a pedagogical university in the sociocultural space of the region ]// Pedagogicheskij IMIDZH [Pedagogical IMAGE]. 2018. No. 2 (39). Pp. 128-137. (In Russian).

5. Doronina I. N. Otsenka kachestva sajta biblioteki kak kanala mezhkul'turnoj kommunikatsii [Assessment of the quality of the library's website as a channel of intercultural communication] // Vestnik KazGUKI [Bulletin of the Kazan State University of Culture and Arts]. 2019. No. 1. Pp. 30-37. (In Russian).

6. Panasyuk A.YU. Formirovanie imidzha: strategiya, psikhotekhnologii, psikhotekhniki [Image building: strategy, psycho-technologies, psycho-technics]. M.: Iz-vo «Omega - L» [Omega-L Publishers], 2009. p. (In Russian). P. 266.

7. Satubaldin A. K. Progressivnye tendentsii v razvitii sovremennogo muzejnogo dela [Progressive trends in the development of modern museum business] // Vestnik KazGUKI [Bulletin of the Kazan State University of Culture and Arts]. 2019. No. 2. Pp. 42-48. (In Russian).

8. Simonova I. F. Osobennosti formirovaniya imidzha uchrezhdeniya kul'turno-dosugovoj sfery [Features of building the image of a cultural and leisure institution]. Nauchnye issledovania: ot teorii k praktike [Scientific research: From theory to practice.], 2015. No. 4 (5). Pp. 273-278. (In Russian).

9. Depelyan R. A. Problemy upravleniya: teoriya i praktika. Faktory, vliyayushchie na formirovanie vnutrennego imidzha organizatsii. [Management problems: theory and practice. Factors influencing the creation of the internal image of the organization]. Gosudarstvennoe upravlenie [Public Administration]. 2017. No. 64. Pp. 68-81. (In Russian).

\section{Наталья Валерьевна Молчанова}

кандидат педагогических наук, дочент кафедры социально-культурной деятельности

Волгоградский государственный институт искусств и культуры

400001, Россия, г. Волгоград,

ул. Циолковского, 4

тел.: +7(8442)974884

\section{Natal'ya V. Molchanova \\ Candidate of Sciences (Pedagogy), Associate Professor of the Department of Social and Cultural Activities}

Volgograd State Institute of Arts and Culture 4 Tsiolkovsky St, Volgograd, Russia, 400001

tel.: $+7(8442) 974884$

Статья поступила в редакцию 04.06.2021 2, одобрена после рецензирования 06.08.2021, принята к публикации 02.09.2021 